\title{
EDITORIAL
}

\section{Urinary Incontinence - Encouraging Women to Seek Help}

\author{
Budi I Santoso
}

Urinary incontinence is a problem that is rarely discussed, either by patients or by health providers. For the patients, it may be embarrassing and distressing, leading to reluctance in disclosing any complaints regarding incontinence. Furthermore, incontinence is believed to be a problem only affecting the elderly. It is often overlooked that this condition can affect anyone, regardless of age, and at any given time.

Women are more prone to incontinence due to the thinning of muscles and the vaginal tissues, which can happen after menopause. When weakened, it will be easier for urine to be accidentally expelled. There is a wide difference in the prevalence of urinary incontinence based on age group. Approximately $25 \%$ of premenopausal women and $40 \%$ of postmenopausal women report leakage of urine. It has been estimated that in young adults, the prevalence of incontinence is around $20-30 \%$, rising substantially to $30-50 \%$ in the elderly. ${ }^{1,2}$ A pooled analysis of epidemiologic studies report the prevalence of urinary incontinence was $21 \%$ in the 14-44 years age group, 34\% in 45-64 years age group and 39\% among elderly women. ${ }^{3}$ Additionally, an estimated one in three women living in assisted living (residential or nursing homes) experience incontinence. ${ }^{4}$ Not all leakage is bothersome to patients; however, $10 \%$ of middle-aged women report daily incontinence, and one-third report weekly incontinence. ${ }^{5}$

Urinary incontinence is defined by the International Continence Society as "any leakage", specifically as any involuntary loss of urine regardless of frequency, quantity and duration of the condition or the degree to which it affects quality of life. The two most common types of urinary incontinence are stress incontinence, the involuntary loss of urine resulting from increased abdominal pressures (such as with a cough or Valsalva's maneuver), and urge incontinence, the involuntary loss of urine after an unwanted contraction of the detrusor muscle. ${ }^{6}$ Urinary incontinence is associated with numerous psychological and social problems and can negatively affect quality of life. Women have reported that it invokes fear, frustration, anxiety, and leading to difficulties in their social life, practicing physical activities, or sexual activities. ${ }^{7}$ A study in Sweden discovered that patients might perceive incontinence as more of a psychosocial nuisance than a health-related problem, thus leading to the underreporting of this problem. ${ }^{8}$

The main problem leading to incontinence is the wider problem of pelvic floor dysfunction. The wider problem of urinary incontinence is pelvic floor dysfunction). Factors contributing to pelvic floor dysfunction include obstetrical trauma, obesity, aging and a multitude of other factors. The spectrum of symptoms resulting from pelvic floor dysfunction includes urinary incontinence, fecal incontinence, and pelvic organ prolapse. These problems almost never occur exclusively and concurrence is a common finding. ${ }^{9}$

Epidemiologic studies have reported prevalence of stress incontinence ranging from $23-67 \%$ during pregnancy and 6-29\% after childbirth, but little is known about how the condition affects women at this time. However, the prevalence of urinary incontinence may be nearly the same 8 weeks postpartum as during pregnancy. ${ }^{10}$

Despite the magnitude of problem caused by urinary incontinence, studies have reported low consultation, diagnosis, and treatment rates are the main reason why urinary incontinence is still a complicated problem in the society. ${ }^{11,12}$ The need for early recognition of this problem is supported by the fact that conservative management is more effective and cheaper in patients with mild symptoms. However, in some women, the diagnosis of incontinence might take years, and some others may never get diagnosed.

To overcome this problem, there is a need for initiative from health providers to identify women who may be at risk for continence problems early on (ie. during the pregnancy) and inquire about incontinence during routine consultation. Furthermore, counseling women and providing knowledge regarding urinary incontinence has also been found of importance in encouraging women to seek help when the need arise. Knowledge has 
been identified as one of the most important factors predicting women's treatment-seeking behavior, even more than socioeconomic factors. Therefore, counseling women on urinary incontinence should not only be the responsibility of physicians, but should also be undertaken by other healthcare providers such as midwives and nurses.

\section{References}

1. Hunskaar S, Arnold EP, Burgio K, et al. Epidemiology and natural history of urinary incontinence. Int Urogynecol J Pelvic Floor Dysfunct 2000; 11: 301-19.

2. Hannestad YS, Rortveit G, Sandvik H, et al. A community-based epidemiological survey of female urinary incontinence: the Norwegian EPINCONT study. Epidemiology of incontinence in the county of Nord-Trøndelag. J Clin Epidemiol 2000; 53: 1150-7.

3. Shamliyan T, Wyman J, Bliss D, et al. Prevention of urinary and fecal incontinence in adults. Evid Rep Technol Assess 2007; null: 1-379.

4. Keegan W. Addressing the problem of urinary incontinence. Pract Nurse 2009; 38(8): 43.

5. Rebecca G, Roger MD. Urinary stress incontinence in women. N Engl J Med 2008; 358: 1029-36.

6. Abrams P, Cardozo L, Fall M, et al. The standardisation of terminology of lower urinary tract function: report from the Standardisation Sub-committee of the International Continence Society. Neurourol Urodyn 2002; 21: $167-78$

7. Buurman MBR, Lagro-Janssen ALM. Women's perception of postpartum pelvic floor dysfunction and their help-seeking behaviour: A qualitative interview study. Scand J Caring Sci 2013; 27: 406-13.

8. Franzen $\mathrm{K}$, Johansson, J-E, Andersson G, et al. Urinary incontinence in women is not exclusively a medical problem: A populationbased study on urinary incontinence and general living conditions. Scand J Urol Nephrol 2009; 43: 226-32.

9. Halverson AL, Boller, A-M. Pelvic floor disorders: scope of the problem. Semin Colon Rect Surg 2010; 21(1): 2-5.

10. Mostwin J, Bourcier A, Haab F, et al. Pathophysiology of urinary incontinence, fecal incontinence, and pelvic organ prolapse. International Continence Society. 2000.

11. Adedokun BO, Morhason-Bello LO, Ojengbede OA, et al. Help-seeking behavior among women currently leaking urine in Nigeria: is it any different from the rest of the world. Patient Prefer Adher 2012; 6: 815-9.

12. Al-Badr A, Brasha H, Al-Raddadi R, et al. Prevalence of urinary incontinence among Saudi women. Int J Gynecol Obs 2012; 117: $160-3$. 